\title{
Habituation of P300 from auditory stimuli
}

\author{
JOHN POLICH \\ Scripps Clinic, La Jolla, California
}

\begin{abstract}
In a series of three experiments, the habituation effects on the P300 or P3 event-related brain potential (ERP) elicited with a simple auditory stimulus discrimination task were evaluated. In Experiment 1, possible changes in the P3 for the first 15 individual target stimulus trials were investigated. Neither the component amplitude or latency changed across trials when the target probability was $10 \%, 30 \%$, or $50 \%$. In Experiment 2, a target probability of $20 \%$ was employed, with 10 blocks of 20 target trials that were collected continuously. P3 amplitude declined significantly between the 1st and 10th trial blocks, with no decrements in target-detection performance observed. P3 latency tended to increase with repeated presentations. Experiment 3 was similar to Experiment 2, but the pitch of the target stimulus was changed after the 9th trial block. P3 amplitude again declined between the 1st and 9th trial blocks, but it increased significantly on the 10th block when the target stimulus changed, thereby demonstrating dishabituation. A second decrease in amplitude occurred by the 15th trial block. P3 latency tended to increase with repeated presentations but decreased with the stimulus change. The P3 component elicited with an active discrimination task and auditory stimuli does habituate after a sufficient number of trials have been presented. The implications of these results for the theoretical interpretation of the P3 are discussed.
\end{abstract}

The P300 or P3 component of the event-related brain potential (ERP) is generated when subjects attend to and discriminate stimulus events that differ from one another on some dimension. It is a large (ca. $10-20 \mu \mathrm{V}$ ), positivegoing potential with a latency of approximately $300 \mathrm{msec}$ when elicited with a simple auditory discrimination task in young adults, and it is of maximal amplitude over the midline central and parietal scalp areas (Polich, 1986a; Pritchard, 1981). While the neural origins of the P3 are still being sought, depth-electrode recordings and magnetic field studies in humans suggest that at least some portion of the $\mathbf{P} 3$ is generated in the medial temporal lobe, most likely including the hippocampus and amygdala structures-brain areas associated with learning and memory (Halgren et al., 1980; McCarthy et al., 1982; Okada, Kaufman, \& Williamson, 1983). Moreover, because the P3 indexes stimulus evaluation, is sensitive to the probability of the eliciting event, and is independent of response selection, it has been interpreted as reflecting memory-updating processes (Donchin, 1981). According to this view, the function of $\mathrm{P} 3$ is to refresh the mental model (or schema) of the environment, since this ERP component "performs tasks that are required in the maintenance of working memory" (Donchin, Karis, Bashore, Coles, \& Gratton, 1986, p. 256). This theoretical interpre-

This work was supported by the Armstrong-McDonald Foundation and NIAAA Grant AA06420 and is contained in Publication 5218BCR from the Research Institute of Scripps Clinic. The thoughtful comments of Walter Ritter on a previous version of this paper are gratefully acknowledged. Address correspondence to J. Polich, Preclinical Neuroscience (BCR1), Scripps Clinic and Research Foundation, 10666 N. Torrey Pines Road, La Jolla, CA 92037. tation has been supported by a variety of studies, which have demonstrated larger P3 amplitudes for stimulus items that produce superior recall relative to control conditions (Fabiani, Karis, \& Donchin, 1986; Karis, Fabiani, \& Donchin, 1984; Neville, Kutas, Chesney, \& Schmidt, 1986), as well as shorter $P 3$ latency for better memory performance in normal and cognitively impaired individuals (Brown, Marsh, \& LaRue, 1982; Howard \& Polich, 1985; Johnson, Pfefferbaum, \& Kopell, 1985; Polich, Ehlers, Otis, Mandell, \& Bloom, 1986; Polich, Howard, \& Starr, 1983; Squires, Galbraith, \& Aine, 1979).

Although usually couched in metaphorical terms, which relate the P3 to a computer subroutine that is called whenever the processing system requires a change in the mental schema of the environment (Donchin, Ritter, \& McCallum, 1978), the context-updating theory is highly similar to models proposed for the orienting reflex (OR). This association is purposeful, since the $O R$ is thought to result from a mismatch between external events and an internal neuronal model (Rohrbaugh, 1984; Sokolov, 1975) - the same sort of explanatory mechanism as that employed for the P3, even though the degree of similarity between the concepts is debated (Donchin et al., 1984; Näätänen, 1979). A major reason for this debate stems from clear habituation effects for OR phenomena (see Siddle, Stephensen, \& Spinks, 1983, and Stephenson \& Siddle, 1983, for elegantly thoughtful reviews) and sensory evoked potentials (Öhman \& Lader, 1977; Picton, Hillyard, \& Galambos, 1976; Roemer, Teyler, \& Shagass, 1984; although see also Näätänen \& Picton, 1987, for an alternative view), with rather ambiguous evidence for $\mathrm{P} 3$ habituation. 
This uncertainty about habituation of the P3 ERP appears to arise from two classes of studies, which have yielded different results: (1) If P3-like potentials are elicited with the simple repetition of a stimulus or by means of infrequent stimuli embedded in a repetitive stimulus series, diminution of their amplitude is readily observed for both auditory (Bourbon, Will, Gary, \& Papanicolaou, 1987; Lutzenberger, Schandry, \& Birbaumer, 1979; Megela \& Teyler, 1979; Polich, 1987a; Ritter, Vaughan, \& Costa, 1968; Roth, 1973; Schandry \& Hoefling, 1979; Woods \& Elmasian, 1986) and visual stimuli (Courchesne, 1978; Courchesne, Courchesne, \& Hillyard, 1978; Elton, Schandry, \& Sparrer, 1983; Kok \& Looren de Jong, 1980; Verbaten, Roelofs, Sjouw, \& Slangen, 1986). Even when each stimulus receives attention by requiring the subject to make a response to all stimulus presentations, the resultant P3-like potentials diminish in amplitude with repeated trials (Becker \& Shapiro, 1980; Roth, Blowers, Doyle, \& Kopell, 1982; Roth, Dorator, \& Kopell, 1984; Verbaten, 1983; Woods, Courchesne, Hillyard, \& Galambos, 1980). (2) However, when $\mathrm{P} 3$ components are elicited by having subjects discriminate target from nontarget stimuli, no change in $\mathrm{P} 3$ amplitude has been found over many trial blocks of stimulus presentations (Pritchard, Brandt, Shappell, O'Dell, \& Barratt, 1986; Tueting \& Levit, 1979), unless task performance also decreases in a concomitant fashionimplying that the $\mathrm{P} 3$ process was not fully engaged due to a lapse of vigilance (Parasuraman, 1983; Rohrbaugh et al., 1987; Wilkinson \& Seales, 1978).

These results indicate that when P3-like components are obtained in a manner similar to the way in which sensory evoked potentials are obtained, amplitude decrements over trials indicative of habituation are observed. However, when the $\mathrm{P} 3$ potential is elicited within the context of an active discrimination task, no decrease in component amplitude or habituation is observed in the absence of a decline in behavioral task performance. A similar lack of rapid decrease in response for other OR measures (skin conductance and heart rate) also has been reported when stimuli are given "signal value" by requiring a discriminative-type response (Bernstein, Taylor, \& Weinstein, 1975; Coles, Sosdian, \& Isaacson, 1972; Hiroshige \& Iwahara, 1978; Ray, Piroch, \& Kimmel, 1977; Siddle, O'Gorman, \& Wood, 1979), although direct comparisons to $P 3$ paradigms are not straightforward (see Siddle et al., 1983, for a thorough discussion). Hence, given the strong conceptual and empirical associations between the OR and P3 (see Roth, 1983), and that a major characteristic of the OR and sensory evoked potentials is a decrease of response amplitude with repeated stimulus trials (Loveless, 1983; Siddle et al., 1983; Stephenson \& Siddle, 1983), it is unclear why the P3 as elicited with a discrimination task should not habituate unless its functional significance is less related to context updating and memory maintenance than has been supposed (Donchin, 1981). If the P3 does index a change in the neural representation of the stimulus environment in a manner similar to that hypothesized for OR manifestations, then it should also evince habituation. The present studies were conducted in an attempt to examine this possibility in a comprehensive fashion.

\section{EXPERIMENT 1}

Although habituation effects per se have not been obtained for P3s elicited with a discrimination task, an important methodological difference between the components obtained in a $\mathbf{P} 3$ paradigm and those used to evaluate the OR is the means by which the ERPs are typically measured. Observation of the P3 component is usually obtained by averaging many target trials (e.g., 20 or more), rather than observing just the first few initial trials and comparing them with subsequent trials to determine whether a decrease in amplitude has occurred-as is usually done for most OR-related phenomena. Thus, it may be that $\mathbf{P} 3$ amplitude does decline initially, and that it remains stable over many trials as sensory evoked potentials do (see, e.g., Fruhstorfer, 1971; Loveless, 1979; Polich, Aung, \& Dalessio, 1988; Rust, 1977; Weber, 1970, Westenberg \& Weinberger, 1976).

Polich (1986b) examined this possibility by evaluating the P3 and other ERP components elicited with a simple auditory discrimination task every two trials for 20 target trials. No differences between the first two-trial averages and later ones for component amplitude or latency were obtained. This result suggested that $\mathrm{P} 3$ habituation did not occur, even though component amplitudes decreased across trials when all the two-trial averages were added together to form the overall ERP. In addition, when reverse averaging was employed to obtain a complete average such that the two-trial averages collected last were used as the initial trials while the trials collected first were added last, no differences between this method and the usual forward averaging procedure were obtained. If habituation of the P3 had been occurring as the overall reverse average was formed, no amplitude declines should have been observed, since the latter trials would have been smaller than the beginning trials in the average.

Although these results indicated that $\mathrm{P} 3$ amplitude did not habituate, it is possible that the two-trial averages precluded observation of any amplitude declines, since much of the reduction in OR responses is found within the first few trials. If this was the case, then examination of single-trial responses might reveal amplitude declines indicative of $\mathrm{P} 3$ habituation that could not be observed with the two-trial method. In the first experiment, P3 responses to single trials were obtained and compared to the overall average for each subject under several levels of target stimulus probability, to assess whether this factor also might affect P3 habituation.

\section{Method}

Subjects. A total of 24 undergraduates (12 males, 12 females) from the University of California at San Diego were employed as subjects (mean age $=22.2 ; S D=2.8$ years). All the subjects 
reported being free of any psychiatric or neurological disorders and were naive to electrophysiological studies; they received course credit for their participation.

Stimuli and Procedure. ERPs were elicited with binaural 1000and $2000-\mathrm{Hz}$ tones presented at $60 \mathrm{~dB}$ SPL $(9.9-\mathrm{msec}$ rise/fall and $50-\mathrm{msec}$ plateau). The target stimulus was always the $2000-\mathrm{Hz}$ tone, and the standard stimulus was always the $1000-\mathrm{Hz}$ tone. The tone stimuli were presented once every $2.0 \mathrm{sec}$. Each subject participated in three different target-stimulus probability conditions $(10 \%$, $30 \%$, or $50 \%$ ), with the presentation order of the different probabilities counterbalanced across subjects within each sex. The subjects were instructed to sit quietly, listen to tones with their eyes closed, and move the index finger of their right hand whenever a target tone was detected. The experimenter noted any incorrectly perceived stimulus trials.

Recording conditions. Electroencephalographic (EEG) activity was recorded at the $\mathrm{Cz}$ electrode site of the 10-20 system using a gold-plated electrode affixed with electrode paste and tape, referred to linked earlobes with a forehead ground and impedances at $10 \mathrm{k} \Omega$ or less. The filter band-pass was $0.5-30 \mathrm{~Hz}(3 \mathrm{~dB}$ down, $12 \mathrm{~dB}$ octave/slope). Bipolar recordings of the electro-ocular activity (EOG) also were made with electrodes placed at the outer canthus and supraorbitally to the left eye. The EEG was digitized at $1.5 \mathrm{msec}$ per point for $750 \mathrm{msec}$ with a $75 \mathrm{msec}$ prestimulus baseline. Waveforms were averaged on-line by a Nicolet Pathfinder II signal averager, which controlled the stimulus presentation and artifact rejection. Trials on which the EEG or EOG exceeded $\pm 45 \mu \mathrm{V}$ were automatically rejected. The subjects were highly cooperative in all task conditions, which resulted in very few trials rejected because of artifactual responses. A total of 15 consecutive single target trials for each probability condition was collected from each subject.

\section{Results and Discussion}

The subjects performed the task virtually without error, since fewer than $0.1 \%$ of the target trials were misperceived; no statistical differences were observed between probability or trial conditions $(p>.70)$. The ERP data were analyzed by first obtaining the overall average for each subject for each probability condition in the usual fashion. The overall average was then used as a template to assess the individual trials from which it was composed. Each individual ERP trial was overlayed with the average from that condition and subject. This process is illustrated in Figure 1 with data from a representative subject. The N1, P2, N2, and P3 components from the single trial were defined as the maximum negative or positive peak (relative to the prestimulus baseline) most closely corresponding to those peaks in the overall average within the latency windows of 80-120,100-200,160-240, and 220-360 msec, respectively (Polich, 1986b). The mean $( \pm 1 S E)$ amplitude and latency values computed across subjects for each of these components are presented in Figure 2. Thus, each point represents the mean of the single trial measurements for that component for all 24 subjects.

A two-factor (trial $\times$ probability) analysis of variance was applied to the component amplitude and latency measures obtained from each subject. For the amplitude values, no differences as a function of trial number were obtained for either the $\mathrm{P} 3$ component $(p>.80)$ or the $\mathrm{N} 1, \mathrm{P} 2$, and $\mathrm{N} 2$ components ( $p>.25$ in all cases). In

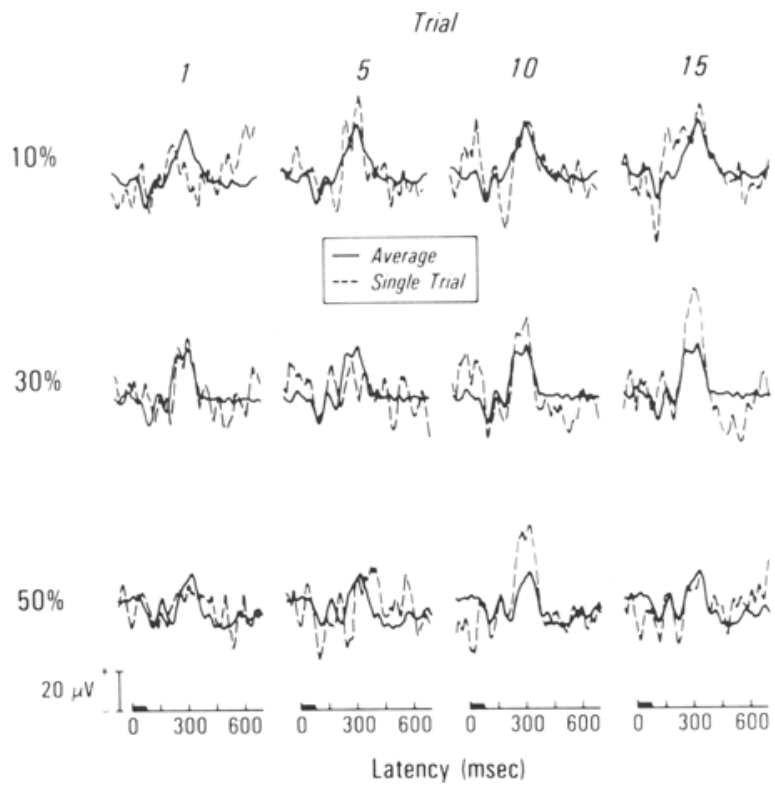

Figure 1. Examples of single-trial event-related potentials and the overall average from the $\mathrm{Cz}$ electrode site for a single representative subject and each probability condition (Experiment 1).

addition, preliminary analyses demonstrated no amplitude changes indicative of $\mathrm{P} 3$ declines over trials when the presentation order of each probability condition was assessed ( $p>.35$ in all cases). Thus, P3 amplitude did not decrease across trials or as a function of the presentation order of trial blocks. The P3 did decrease in amplitude significantly as the target probability increased (25.2, 23.0 , and $21.8 \mu \mathrm{V})$, with $F(2,36)=6.5$, and $p<.005$. A similar effect of probability also was observed for $\mathrm{N} 2$ amplitude $(11.5,11.8$, and $11.1 \mu \mathrm{V})$, with $F(2,36)=4.1$, and $p<.05$, as well as a significant albeit weak interaction between probability and trial $[F(28,504)=1.5$, $p<.05$ ]. No other reliable amplitude effects were obtained for any of the other potentials. For the latency values, the $\mathrm{P} 3$ component demonstrated a significant effect of trial number $[F(14,252)=2.3, p<.01]$. Trial number and probability also produced significant main effects for the $\mathrm{P} 2$ potential, and these two variables demonstrated a significant interaction for the $\mathrm{N} 1$ component ( $p<.05$ in all cases). However, given the relatively consistent pattern for the latency effects, illustrated in the lower portion of Figure 2, and the weak statistical nature of the findings, it is reasonable to assume that the latency trial effects are more spurious than real.

The lack of amplitude change across trials indicates that the P3 ERP component did not habituate with repeated single-trial presentations of the target stimulus, and it confirms a previous report employing similar procedures (Polich, 1986b). That the decrease in amplitude expected to occur with increases in target probability was observed across the 15 single trials obtained for each probability level suggests that the procedures used to elicit the P3 and measure the individual trials were producing accurate 


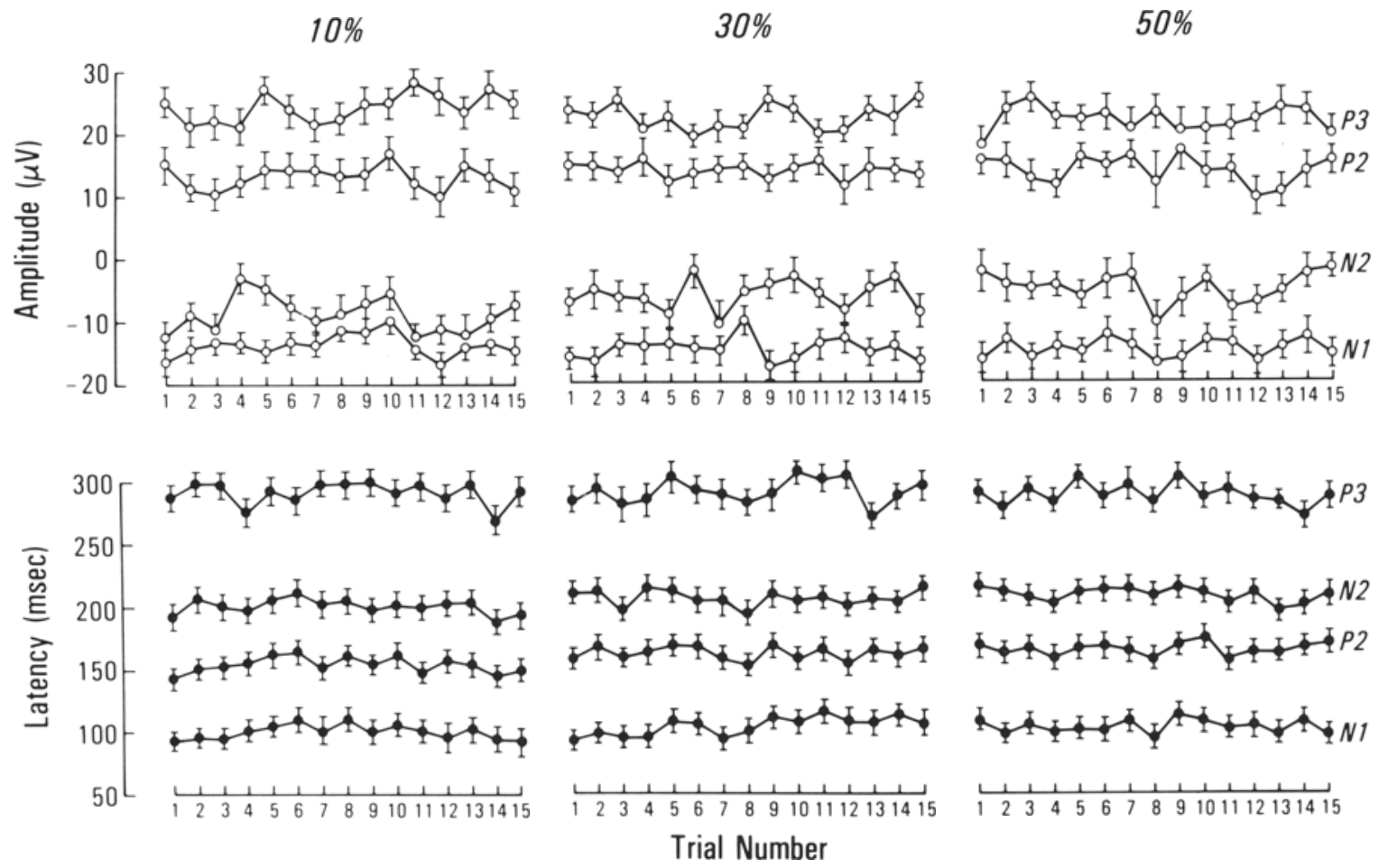

Figure 2. Mean $( \pm 1 S E)$ component amplitudes and latencies from 15 single-target trials averaged over all $(N=24)$ subjects for each probability condition (Experiment 1).

results (Duncan-Johnson \& Donchin, 1977). However, as indicated by the relatively flat amplitude profiles portrayed in Figure 2, component amplitudes for the P3 as well as the $\mathrm{N} 1, \mathrm{P} 2$, and $\mathrm{N} 2$ potentials did not change between the initial and subsequent target-stimulus presentations. Although some changes across trial number for component latency were obtained, these were generally not strongly related to target-trial progression. Rather, the wide intersubject variation for the single-trial measures of component latency appeared to produce inconsistent fluctuations in mean latency values which were manifested with weak statistical outcomes. Thus, relatively little change in ERP values were observed as a function of individual target trials.

\section{EXPERIMENT 2}

Previous studies that have found P3 amplitude decrements as time-on-task increased also demonstrated concomitant decreases in task performance often induced by relatively difficult and boring task situations used to assess vigilance performance (Parasuraman, 1983; Rohrbaugh et al., 1987; Wilkinson \& Seales, 1978). These results imply that changes in attentional factors may have contributed to the amplitude decline (Donchin, Kramer, \& Wickens, 1986; Kramer, Schneider, Fisk, \& Donchin, 1986). Other studies, in which $P 3$ habituation with repeated trial blocks was not found, may have established insufficient habituation conditions because of atypically long interstimulus intervals (7 sec; Pritchard et al., 1986), which can affect P3 amplitude (Fitzgerald \& Picton, 1981; Polich, 1987c), or because of the use of a guessing task that required an interruption of stimulus presentation so that the subjects could verbally report their predictions about the forthcoming target (Tueting \& Levit, 1979). These procedures may have maintained the need for changes in the neuronal model of the environment, thereby precluding a decline in $\mathrm{P} 3$ amplitude. Hence, none of these studies has been able to establish whether the P3 ERP component changes in amplitude with repeated target presentations when the subject's task performance is maintained across trial blocks. In the second experiment, a simple auditory discrimination task was used with a relatively short interstimulus interval for an extended number of trial blocks, to determine if habituation of the $\mathrm{P} 3$ could be observed.

\section{Method}

The same subjects employed in Experiment 1 were used for the second study, which was conducted after a short break. The same recording parameters and stimulus conditions also were used, with the exception that the target tone occurred randomly on $20 \%$ of the stimulus trials. The subjects were presented stimulus items continuously without interruption, until 10 individual trial blocks composed of 20 target trials were collected. All other conditions were identical to those in the first study.

\section{Results and Discussion}

Task performance exhibited very few errors, with fewer than $1.0 \%$ of the targets misperceived across subjects and trials and no differences between trial blocks observed 


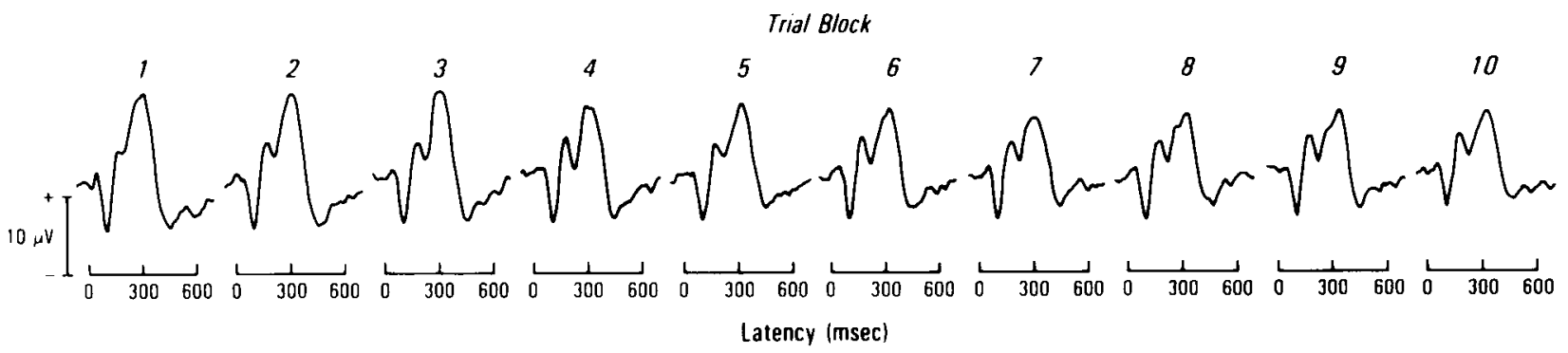

Figure 3. Grand average ERPs from the Cz electrode site, taken over all subjects $(N=24)$ for each trial block composed of 20 targetstimulus presentations from each subject (Experiment 2).

$(p>.30)$. The grand averaged ERPs obtained from each subject for each successive trial block of 20 target trials are presented in Figure 3. Component amplitudes and latencies for the $\mathrm{N} 1, \mathrm{P} 2, \mathrm{~N} 2$, and $\mathrm{P} 3$ potentials were assessed using the latency criteria as in the first study. Their mean values $( \pm 1 S E)$ are illustrated in Figure 4 as a function of trial block. A one-factor (trial block) analysis of variance was applied to the amplitude and latency data for each component. Newman-Keuls post hoc procedures were then used to evaluate the locus of any statistical effects.

As suggested by the ERPs in Figure 3 and the mean component values in Figure 4, P3 amplitude demonstrated a substantial decline across trial blocks. This observation was confirmed by a highly significant main effect for trial

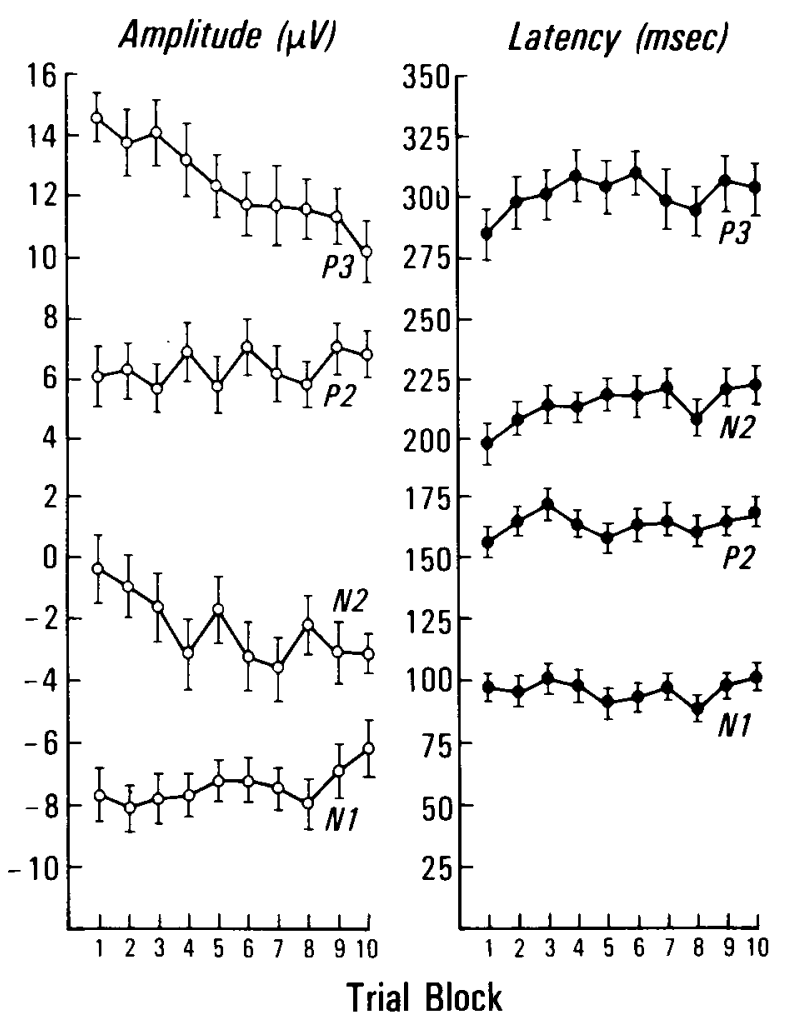

Figure 4. Mean $( \pm 1 S E)$ component amplitudes and latencies for each trial block averaged over all $(N=24)$ subjects (Experiment 2). block $[F(9,207)=5.3, p<.0001]$. In addition, post hoc analysis revealed that Trial Blocks 1 through 4 had significantly larger amplitudes than Trial Blocks 6 through $10(p<.05)$. The only other amplitude main effect was for the $\mathrm{N} 2$ component $[F(9,207)=2.5, p<.05]$, with Trial Block 1 found to be significantly smaller than Trial Blocks 6 and $7(p<.05)$. No statistically reliable differences for P3 latency were observed across trial blocks, although a marginal increase was found $[F(9,207)=1.8$, $p=.07]$. N1 component latency yielded an overall significant trial block effect $[F(9,207)=4.5, p<.001]$, with the post hoc tests demonstrating that Trial Blocks 3 and 10 were significantly longer in latency than Trial Blocks 2, 5, 6, and $8(p<.05)$. N2 component latency also produced a significant trial block effect $[F(9,207)=$ $2.7, p<.01$ ], with the post hoc test revealing that Trial Block 1 was significantly shorter in latency than Trial Blocks 5, 6, 7, 9, and 10 .

These results indicate that the P3 ERP component decreased in amplitude with repeated presentations of the target stimulus in the absence of declines in performance. This decrease occurred without any strong shifts in peak latency, although a tendency toward longer latencies across trial blocks was observed. An increase in N2 amplitude as trial blocks increased also was obtained; but this effect was relatively weak, and it appears to be yoked to the overall decline in P3 amplitude. The only other effects originating from increases in the number of trial blocks were increases in the latency of the $\mathrm{N} 1$ and $\mathrm{N} 2$ components. These general delays of the earlier components may be related to the slight delay of the $P 3$ potential. Given the robust effect of P3 amplitude decreases as trial blocks increased, however, it seems safe to conclude that this ERP component does habituate with repeated target-trial presentations. The implications of this finding will be examined below.

\section{EXPERIMENT 3}

Experiment 1 demonstrated that the P3 ERP elicited with a simple auditory discrimination task does not change over the initial few single trials, unlike other OR phenomena. Experiment 2 found that declines in P3 amplitude do occur with repeated presentations of the target stimuli, even when task performance remains relatively 
constant across trial blocks. Thus, habituation of P3 amplitude can be obtained in a manner similar to that for other aspects of the OR, except that it is observed after a comparatively large number of stimulus presentations.

The latter result suggests that the decrease in P3 amplitude with repeated target stimulus presentations may stem not from habituation processes, but rather from receptor or sensory system fatigue (Loveless, 1983; Megela \& Teyler, 1979; Stephenson \& Siddle, 1983). The classic means of distinguishing between response decrements due to habituation from sensory processing declines involves dishabituation procedures, wherein the habituated response is reinstated by means of a change in the repeated stimulus. If the response returns or exceeds baseline levels, then its decline can be attributed to habituation effects because the neuronal model has been changed with the introduction of the new stimulus. If the response is not affected, then the original decline is most likely due to fatigue of the sensory system. Experiment 3 employed a dishabituation procedure with a new group to assess this possibility for the $\mathrm{P3}$. In addition, the midline scalp distribution for the P3 also was obtained across habituation and dishabituation trial blocks to permit evaluation of possible effect differences for electrode location.

\section{Method}

A new group of 16 subjects (with an equal number of each sex) were obtained from the same source as the previous studies (mean age $=21.0, S D=2.1$ ). The same recording conditions as those in Experiment 2 were employed, except that the $\mathrm{Fz}, \mathrm{Cz}$, and $\mathrm{Pz}$ electrode sites also were used. To permit the assessment of the additional electrode locations, 20 target-trial presentations were collected for Trial Blocks 1, 5, 9, 10, and 15, with the intervening ERP trial blocks discarded, although task performance was moni- tored. All the subjects were presented with the $1000-\mathrm{Hz}$ tone as the standard stimulus. One half the subjects were presented with a $2000-\mathrm{Hz}$ tone as the target stimulus for Trial Blocks 1 through 9 and a 500-Hz tone for Trial Blocks 10 through 15. The other half of the subjects were presented the reverse arrangement, with the $500-\mathrm{Hz}$ tone as the target for Trial Blocks 1 through 9 and the 2000 $\mathrm{Hz}$ tone for Trial Blocks 10 through 15 . Thus, the habituation trials were 1 through 9, with a dishabituating stimulus presented on Trial Block 10 and then continuing until the end of the experiment. The subjects were instructed to move their index finger to the non$1000-\mathrm{Hz}$ tone and told that the tone frequency would change sometime during the stimulus series. All other aspects of Experiment 3 were identical to those of the previous experiments.

\section{Results and Discussion}

Task performance was again very good, with $1.1 \%$ of the target tones misperceived across trial blocks and conditions $(p>.35)$. The grand averaged ERPs for each electrode location and Trial Blocks 1, 5, 9, 10, and 15 are presented in Figure 5. The amplitudes and latencies for the N1, P2, N2, and P3 components were obtained in the same fashion as Experiment 2. The mean amplitude and latency results $( \pm 1 / 2 S E)$ are presented in Figure 6 . These data were analyzed initially with a twofactor (electrode $\times$ trial block) analysis of variance. The data from each electrode location were then assessed with separate one-factor (trial block) analyses of variance (Wood \& McCarthy, 1984); Newman-Keuls post hoc comparisons were employed to determine the sources of specific effects for the results from the $\mathrm{Cz}$ electrode site, as was done in Experiments 1 and 2.

For the $\mathrm{P} 3$ amplitude data, the pattern illustrated in Figure 6 yielded an overall significant difference for the trial-block factor $[F(4,60)=6.5, p<.001]$. The typical increase in component amplitude from the frontal to

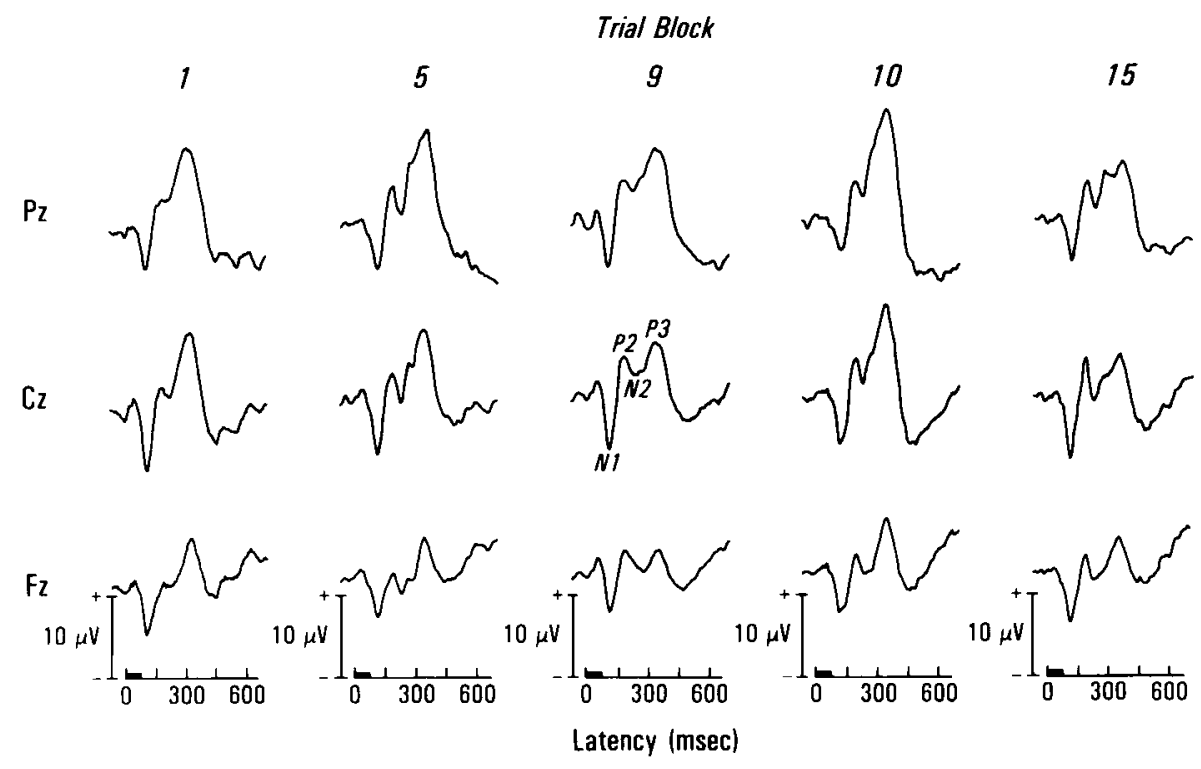

Figure 5. Grand average ERPs for each recording site, taken over all subjects $(N=16)$ for Trial Blocks 1, 5, 9, 10, and 15, each of which was composed of 20 target trials (Experiment 3). 

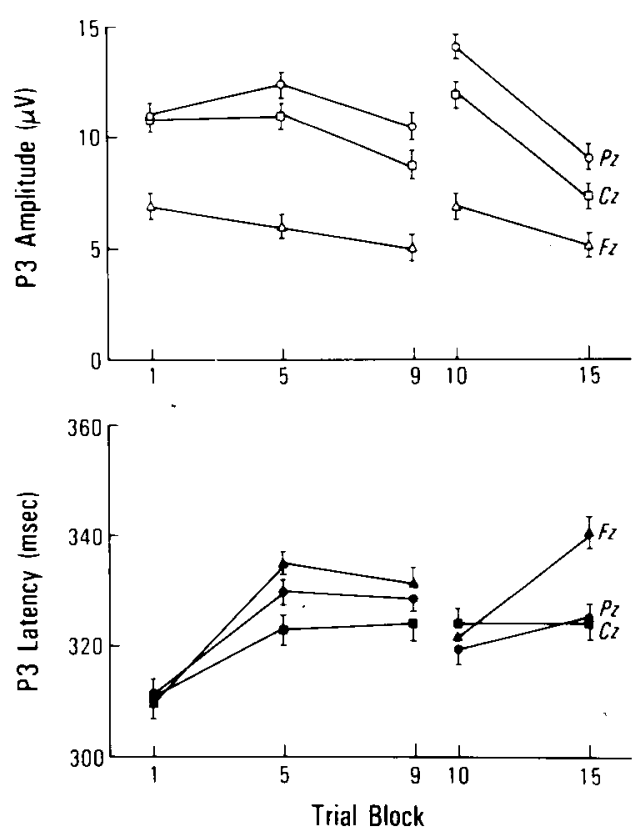

Figure 6. Mean $\left( \pm^{1 / 2} S E\right)$ component amplitudes and latencies, taken over all $(N=16)$ subjects for Trial Blocks $1,5,9,10$, and 15, each of which was composed of 20 target trials (Experiment 3).

the parietal electrode sites also produced a significant main effect $[F(2,30)=43.6, p<.001]$, with a significant interaction found between trial block and electrode site $[F(8,120)=5.6, p<.001]$. Assessment of the individual electrodes confirmed the overall analysis for the trial-block factor, with main effects obtained for the $\mathrm{Fz}, \mathrm{Cz}$, and $\mathrm{Pz}$ recording sites ( $p<.005$ in all cases). Post hoc comparisons performed only on Trial Blocks 1,5 , and 9 indicated that Trial Block 9 yielded significantly smaller $\mathrm{P} 3$ amplitudes than either Trial Block 1 or $5(p<.05)$-a result that replicates the amplitude decreases due to habituation observed in Experiment 2. Moreover, post hoc tests also demonstrated that the increase in $\mathrm{P} 3$ amplitude obtained between Trial Blocks 9 and 10 was significant $(p<.01)$, suggesting that the change in target-stimulus frequency at this juncture produced a dishabituation effect. In addition, Trial Blocks 1,5 , and 10 were significantly larger than Trial Block $15(p<.01)$, supporting the conclusion that $\mathrm{P} 3$ amplitude again declined after the dishabituating target stimulus change.

For the P3 latency data, the general increase observed across trial blocks produced a significant main effect for that factor $[F(4,60)=2.5, p<.05]$. The decrease in latency across electrode sites observed for this task situation (Polich, 1986a; Polich, 1987b) also was obtained $[F(2,30)=3.5, p<.05]$, although this factor and trial block did not interact reliably $(p=.08)$. Assessment of the individual electrodes demonstrated an overall significant increase in P3 latency for the Fz electrode only $[F(4,60)=3.3, p<.02]$, with no reliable effects found for the $\mathrm{Cz}$ and $\mathrm{Pz}$ electrode sites ( $p>.10$ in both cases). Post hoc comparisons supported these findings, with no trial-block effects obtained for the $\mathrm{Cz}$ electrode. Hence, P3 latency tended to become longer with repeated presentations and decreased somewhat after the dishabituating stimulus change, although these latency effects were not robust.

A one-factor (trial block) analysis of variance was applied separately to the N1, P2, and N2 amplitude and latency measures from the $\mathrm{Cz}$ electrode site. For the amplitude data, no overall significant effects were obtained for any of the components, although the N2 potential tended to decrease in amplitude with repeated presentations $(p=.07)$. For the latency data, the $\mathrm{N} 2$ component demonstrated an overall increase $[F(4,60)=3.4$, $p<.02$ ], with post hoc comparisons indicating that Trial Block 1 was significantly shorter in latency than Trial Blocks 9 and 10 ( $p<.05$ in both cases). No other latency effects were observed for these components.

The findings in Experiment 3 replicated the habituation effects of Experiment 2 and also demonstrated an increase in P3 amplitude when the target-tone stimulus was changed. This increase appears to reflect the dishabituation of the P3 in a manner similar to that for other OR and evoked potential responses (Loveless, 1983; Megela \& Teyler, 1979; Stephensen \& Siddle, 1983). These effects were also similar for all three electrode locations, suggesting that the decline and dishabituating increase in amplitude for the P3 ERP was a general phenomenon rather than restricted to either the frontal or centralparietal aspects of the component. Thus, the results of Experiment 3 indicate that the $P 3$ component mimics the responses of phenomena related to the OR, in that it declines in its amplitude with repeated presentation of the eliciting stimulus but can recover to its original levels with a change in the target-stimulus parameters.

\section{GENERAL DISCUSSION}

The major purpose of the present studies was to determine whether the P3 component of the ERP would demonstrate a decline in amplitude with repeated target-stimulus presentations, which could therefore be considered as habituation. The three experiments found that (1) there was no evidence of $\mathrm{P} 3$ habituation when the first 15 single trials were assessed; (2) the P3 declined in amplitude after approximately 200 target stimuli had been presented, implying that it does habituate; and (3) habituation of P3 amplitude was reversed with the presentation of a new target stimulus, which produced a dishabituation effect. Although relatively many stimulus presentations were required to demonstrate these amplitude changes, it seems reasonable to conclude that the P3 ERP did habituate and dishabituate in a manner very similar to that for measures of the OR.

These findings suggest that the context-updating model used to account for a variety of empirical findings obtained for the P3 component (Donchin, 1981; Donchin, Karis, et al., 1986) may be related to the same fundamental mechanisms as those which underlie the $\mathrm{OR}$, since both 
constructs are thought to result from a mismatch between external events and an internal neural model (Rohrbaugh, 1984; Sokolov, 1975). Even though the exact relationship between the P3 and the OR has yet to be specified precisely (cf. Donchin et al., 1984; Loveless, 1983; Näätänen, 1979; Roth, 1983), the degree of similarity between the phenomena is enhanced by the present results because the properties of habituation and dishabituation for the P3 have been observed. The present findings also support many previous studies that have demonstrated the association of the $\mathrm{P} 3$ component to memory performance (Fabiani et al., 1986; Johnson et al., 1985; Karis et al., 1984; Neville et al., 1986) and individual differences in cognitive function (Brown et al., 1982; Howard \& Polich, 1985; Polich et al., 1986; Polich et al., 1983; Squires et al., 1979), since habituation is considered a basic form of memory and learning. Thus, the interpretation of P3 amplitude as reflecting changes in the mental model or schema of the environment whenever working memory is employed is strengthened because the P3 also appears to react similarly to the way in which the other primary indices of nervous system memory embodied by the OR react.

Despite the congenial nature of the association between the P3 and OR suggested by the present data, many more stimulus presentations are required before the $\mathrm{P} 3$ evinces a decline in amplitude compared with only a few trials necessary to observe a similar response for most OR measures. Indeed, in Experiment 1 and a previous study (Polich, 1986b) no change was found in either P3 amplitude or latency for the initial target-stimulus presentations. Only when the target stimulus had been presented many times without a long interval or interruptions between stimuli-which would have disrupted habituation, perhaps by causing a change in the neuronal model in a manner similar to dishabituation (Pritchard et al., 1986; Teuting \& Levit, 1979) - were the decrements in P3 amplitude observed to maintain relatively constant performance across trials with simple and constant task conditions (cf. Parasuraman, 1983; Rohrbaugh et al., 1987; Wilkinson \& Seales, 1978). This result contrasts with sensory evoked potentials, which manifest significant declines in amplitude over just a few stimulus presentations (Näätänen \& Picton, 1987; Öhman \& Lader, 1977; Picton et al., 1976; Roemer et al., 1984) and P3-like potentials generated without some form of active discrimination task (Becker \& Shapiro, 1980; Bourbon et al., 1987; Courchesne, 1978; Courchesne et al., 1978; Elton et al., 1983; Kok \& Looren de Jong, 1980; Lutzenberger et al., 1979; Megela \& Teyler, 1979; Polich, 1987a; Ritter et al., 1968; Roth, 1973; Roth et al., 1982, 1984; Schandry \& Hoefling, 1979; Verbaten, 1983; Verbaten et al., 1986; Woods et al., 1980; Woods \& Elmasian, 1986). However, it is somewhat similar to the larger responses and slower habituation found for OR paradigms that require a response that imparts signal value to the stimulus (Bernstein et al., 1975; Coles et al., 1972; Hiroshige \& Iwa- hara, 1978; Ray et al., 1977; Siddle et al., 1979), in a manner similar to the notion of stimulus "task relevance" for the P3 ERP (cf. Roth, 1983; Siddle et al., 1983). Although direct comparisons between active P3 paradigms and these OR studies are limited by important methodological differences, the maintenance of P3 amplitude elicited with an active discrimination task over many target-stimulus presentations does seem to mimic other signal-value OR phenomena.

The reasons for the continual production of a robust P3 after a great number of target stimuli may stem from the P3's sensitivity to the processing demands in terms of attentional capacity required for the task situation (Donchin, Kramer, \& Wickens, 1986). Because P3 amplitude will decline when attentional resources are directed toward other tasks (Isreal, Wickens, Chesney, \& Donchin, 1980; Wickens, Kramer, Vanasse, \& Donchin, 1983) or when processing becomes well practiced (Kramer et al., 1986), it may be the case that habituation effects do not occur as soon as they do for most OR manifestations because of the attentional requirements necessary to perform the discrimination task. Without such requirements, P3 amplitude declines swiftly in a manner similar to other OR measures and evoked responses. When the subject must continually employ attentional resources to engage in accurate task performance, P3 amplitude remains stable, since the contents of working memory are being deployed to determine whether a target stimulus was presented on each trial. However, after at least several scores of target trials, P3 amplitude begins to decline even though task performance is accurate, because fewer attentional resources may be required to maintain working memory. Moreover, if the context is changed with a dishabituating stimulus, component amplitude is restored because attentional resources are again needed to maintain working memory. Thus, the P3 ERP elicited by means of a discrimination task, while exhibiting properties similar to other OR phenomena from which it obtains its strong theoretical background, is different in that it appears much more sensitive to the attentional processes required to perform the task that brings the potential into being.

\section{REFERENCES}

BeCKer, D. E., \& SHAPIRo, D. (1980). Directing attention toward stimuli affects P300 but not the orienting response. Psychophysiology, 17, 385-389.

Bernsten, A. S., Taylor, K. W., \& WeInsteIn, E. (1975). The phasic electrodermal response as a differentiated complex reflecting stimulus significance. Psychophysiology, 12, 158-169.

Bourbon, W. T., Will, K. W., Gary, H. E., \& Papanicolaou, A. (1987). Habituation of auditory event-related potentials: A comparison of self-initiated and automated stimulus trains. Electroencephalography \& Clinical Neurophysiology, 66, 160-166.

Brown, W. S., MARSh, J. T., \& LARUE, A. (1982). Event-related potentials in psychiatry differentiating depression and dementia in the elderly. Bulletin of the Los Angeles Neurological Society, 47, 91-107.

Coles, M. G. H., Sosdian, B. J., \& IsaAcson, I. J. (1972). Heart rate and skin conductance responses to signal and nonsignal stimuli. Psychonomic Science, 29, 23-24. 
Courchesne, E. (1978). Changes in P3 waves with event repetition: Long-term effects on scalp distribution and amplitude. Electroencephalography \& Clinical Neurophysiology, 45, 754-766.

Courchesne, E., Courchesne, R. Y., \& Hillyard, S. A. (1978). The effects of stimulus deviation on P3 waves to easily recognized stimuli. Neuropsychologia, 16, 189-199.

Donchin, E. (1981). Surprise! ... Surprise? Psychophysiology, 18, 493-513.

Donchin, E., Heffley, E., Hillyard, S. A., Loveless, N., Maltzman, I., Öhman, A., Rösler, F., RuChKIN, D., \& SidDle, D. (1984). Cognition and event-related potentials: II. The orienting reflex and P300. In R. Karrer, J. Cohen, \& P. Tueting (Eds.), Brain and information: Event-related potentials (Vol. 425, pp. 39-57). New York: New York Academy of Sciences.

Donchin, E., Karis, D., Bashore, T. R., Coles, M. G. H., \& GratTon, G. (1986). Cognitive psychophysiology and human information processing. In M. G. H. Coles, E. Donchin, \& S. W. Porges (Eds.), Psychophysiology: Systems, processes, and applications (pp. 244-267). New York: Guilford Press.

Donchin, E., Kramer, A. F., Wickens, C. (1986). Applications of brain event-related potentials in engineering psychology. In M. G. H. Coles, E. Donchin, \& S. W. Porges (Eds.), Psychophysiology: Systems, processes, and applications (pp. 702-718). New York: Guilford Press.

Donchin, E., Ritter, W., \& McCallum, C. (1978). Cognitive psychophysiology: The endogenous components of the ERP. In E. Callaway, P. Tueting, \& S. Koslow (Eds.), Brain event-related potentials in man (pp. 349-411). New York: Academic Press.

Duncan-Johnson, C. C., \& Donchin, E. (1977). On quantifying surprise: The variation in event-related potentials with subjective probability. Psychophysiology, 14, 456-467.

Elton, M., SchandRY, R., \& SparRer, B. (1983). A comparative investigation of ERP components and the SCR in a habituation and dishabituation paradigm. International Journal of Neuroscience, 22, 55-62.

Fabiani, M., Karis, D., \& Donchin, E. (1986). P300 and recall in an incidental memory paradigm. Psychophysiology, 23, 298-314.

Fitzgerald, P. G., \& Picton, T. W. (1981). Temporal and sequential probability in evoked potential studies. Canadian Journal of Psychology, 35, 188-200.

FRUHSTORFER, J. (1971). Habituation and dishabituation of the human vertex response. Electroencephalography \& Clinical Neurophysiology, 30, 306-312.

Halgren, E., Squires, N., Wilson, C., Rohrbaugh, J., Babb, T., \& Crandall, P. (1980). Endogenous potentials in the human hippocampal formation and amygdala by infrequent events. Science, 210, 803-805.

Hiroshige, Y., \& IWAHARA, S. (1978). Digital and cephalic vasomotor orienting responses to indifferent, signal, and verbal stimuli. Psychophysiology, 15, 226-232.

Howard, L., \& Polich, J. (1985). P300 latency and memory span development. Developmental Psychology, 21, 283-289.

Isreal, J. B., Wickens, C. D., Chesney, G. L., \& Donchin, E. (1980). The event-related brain potential as an index of displaymonitoring workload. Human Factors, 22, 211-224.

Johnson, R., Pfefferbaum, A., Kopell, B. S. (1985). P300 and long-term memory: Latency predicts recognition performance. Psychophysiology, 22, 447-507.

KARIS, D., FABIANI, M., \& DonCHIN, E. (1984). "P300" and memory: Individual differences in the von Restorff effect. Cognitive Psychology, 16, 177-216.

KoK, A., \& LOOREN DE JoNG, H. (1980). The effect of repetition of infrequent and unfamiliar visual patterns on components of the eventrelated brain potential. Biological Psychology, 10, 167-188.

Kramer, A., Schneider, W., Fisk, A., \& Donchin, E. (1986). The effects of practice and task structure on components of the event-related brain potential. Psychophysiology, 23, 33-42.

LOVELESS, N. E. (1979). Event-related slow potentials of the brain as expressions of orienting function. In H. D. Kimmel, E. H. Van Olst, \& J. F. Orlebeke (Eds.), The orienting reflex in humans (pp. 77-99). New York: Wiley.
LoveLEss, N. E. (1983). The orienting response and evoked potentials in man. In D. Siddle (Ed.), Orienting and habituation: Perspectives in human research (pp. 71-107). New York: Wiley.

Lutzenberger, W., Schandry, R., Birbaumer, N. (1979). Habituation of the components of the AEP to stimuli of different intensities. In H. D. Kimmel, E. H. Van Olst, \& J. F. Orlebeke (Eds.), The orienting reflex in humans (pp. 123-128). New York: Wiley.

MCCarthy, G., Wood, C. C., Allison, T., GofF, W. R., WilliamSON, P. D., \& SPENCER, D. D. (1982). Intracranial recordings of eventrelated potentials in humans engaged in cognitive tasks. Neuroscience Abstracts, 8, 976

MegelA, A. L., \& Teyler, T. J. (1979). Habituation and the human evoked potential. Journal of Comparative \& Physiological Psychology, 93, 1154-1170.

NXÄTANEN, R. (1979). Orienting and evoked potentials. In H. D Kimmel, E. H. Van Olst, \& J. F. Orlebeke (Eds.), The orienting reflex in humans (pp. 61-75). New York: Wiley.

NẌÄTÄNEN, R., P1CTON, T. (1987). The Nl wave of the human electric and magnetic response to sound: $A$ review and an analysis of the component structure. Psychophysiology, 24, 375-425.

Neville, H. J., Kutas, M., Chesney, G., Schmidt, A. L. (1986). Event-related brain potentials during initial encoding and recognition memory of congruous and incongruous words. Journal of Memory \& Language, 25, 75-92.

ÖHMAN, A., \& LADER, M. (1977). Short-term changes of the human auditory evoked potentials during repetitive stimulation. In J. E. Desmedt (Ed.), Auditory evoked potentials in man. Psychopharmacology correlates of EPs. Progress in clinical neurophysiology (Vol. 2, pp. 93-118). Basel: Karger.

OKada, Y. C., Kaufman, L., \& Williamson, S. J. (1983). The hippocampal formation as a source of the slow endogenous potentials. Electroencephalography \& Clinical Neurophysiology, 55, 417-426.

Parasuraman, R. (1983). Sustained attention in detection and discrimination. In R. Parasuraman \& D. R. Davies (Eds.), Varieties of attention (pp. 243-271). New York: Academic Press.

Picton, T. W., Hillyard, S. A., Galambos, R. (1976). Habituation and attention in the auditory system. In W. D. Keidel \& W. D. Neff (Eds.), Handbook of sensory physiology (Vol. 5, pp. 343-389). Berlin: Springer-Verlag.

PoLICH, J. (1986a). Normal variation of $\mathrm{P} 300$ from auditory stimuli. Electroencephalography \& Clinical Neurophysiology, 65, 236-240.

Polich, J. (1986b). P300 development from auditory stimuli. Psychophysiology, 23, 590-597.

Polich, J. (1987a). Comparison of P300 from a passive tone sequence paradigm and an active discrimination task. Psychophysiology, 24, 41-46.

Polich, J. (1987b). Response mode and P300 from auditory stimuli. Biological Psychology, 25, 61-71.

PoLICH, J. (1987c). Task difficulty, probability, and inter-stimulus interval as determinants of $\mathbf{P} 300$ from auditory stimuli. Electroencephalography \& Clinical Neurophysiology, 68, 311-320.

Polich, J., Aung, M., \& Dalessio, D. J. (1988). Long latency auditory evoked potentials: Intensity, inter-stimulus interval, and habituation. Pavlovian Journal of Biological Science, 23, 35-40.

Polich, J., Ehlers, C. E., Otis, S., Mandell, A. J., \& Bloom, F. E. (1986). P300 reflects the degree of cognitive decline in dementing illness. Electroencephalography \& Clinical Neurophysiology, 63, 138-144.

Polich, J., Howard, L., \& StarR, A. (1983). P300 latency correlates with digit span. Psychophysiology, 20, 665-669.

PritchaRD, W. S. (1981). Psychophysiology of P300. Psychological Bulletin, 89, 506-540.

Pritchard, W. S., Brandt, M. E., Shappell, S. A., O'Dell, T. J., \& Barratt, E. S. (1986). No decrement in visual P300 amplitude during extended performance of the oddball task. International Journal of Neuroscience, 29, 199-204.

Ray, R. L., Piroch, J. F., \& Kimmel, H. D. (1977). The effect of task and stimulus variability on habituation of electrodermal and vasomotor reactions. Physiological Psychology, 5, 189-196.

Ritter, W., Vaughan, H. G., \& Costa, L. D. (1968). Orienting and habituation to auditory stimuli: A study of short term changes in aver- 
aged evoked responses. Electroencephalography \& Clinical Neurophysiology, 25, 550-556.

Roemer, R. A., Teyler, T. J., \& Shagass, C. (1984). Do human evoked potentials habituate? In H. Pecke \& L. Petrinovich (Eds.), Habituation, sensitization, and behavior (pp. 325-346). New York: Academic Press.

Rohrbaugh, J. W. (1984). The orienting reflex: Performance and central nervous system manifestations. In R. Parasuraman \& D. R. Davies (Eds.), Varieties of attention (pp. 323-373). New York: Academic Press.

Rohrbaugh, J. W., Stapleton, J. M., Parasuraman, R., Zubovic, E. A., Frowein, H. W., Varner, J. L., Adinoff, B., Lane, E. A., EckardT, M. J., \& Linnolla, M. (1987). Dose-related effects of ethanol on visual sustained attention and event-related potentials. Alcohol, 4, 293-300.

RoTH, W. T. (1973). Auditory evoked responses to unpredictable stimuli. Psychophysiology, 10, 125-138.

Roth, W. T. (1983). A comparison of P300 and skin conductance response. In A. W. K. Gaillard \& W. Ritter (Eds.), Tutorials in ERP research: Endogenous components (pp. 177-199). Amsterdam: NorthHolland Publishing.

Roth, W. T., Blowers, G. H., DOYle, C. M., \& Kopell, B. S. (1982). Auditory stimulus intensity effects on components of the late positive complex. Electroencephalography \& Clinical Neurophysiology, 54, 132-146.

Roth, W. T., Dorato, K. H., Kopell, B. S. (1984). Intensity and task effects on evoked physiological responses to noise bursts. Psychophysiology, 21, 466-481.

Rust, J. (1977). Habituation and the orienting response in the auditory cortical evoked potential. Psychophysiology, 14, 123-126.

SCHANDRY, R., HoEFLing, S. (1979). Interstimulus interval length and habituation of the P300. In H. D. Kimmel, E. H. Van Olst, \& J. F. Orlebeke (Eds.), The orienting reflex in humans (pp. 129-134). New York: Wiley

Siddle, D. A. T., O'Gorman, J. G., \& Wood, L. (1979). Effects of electrodermal lability and stimulus significance on electrodermal response amplitude to stimulus change. Psychophysiology, 16, 520-527.

Siddle, D. A. T., Stephenson, D., \& Sinks, J. A. (1983). Elicitation and habituation of the orienting response. In D. Siddle (Ed.), Orienting and habituation: Perspectives in human research (pp. 109182). New York: Wiley.

SokoLov, E. N. (1975). The neuronal mechanisms of the orienting reflex. In E. N. Sokolov \& O. S. Vinogradova (Eds.), Neuronal mechanisms of the orienting reflex (pp. 217-238). Hillsdale, $\mathrm{NJ}$ : Erlbaum.

SQUires, N., Galbrarth, G., A ANR, C. (1979). Event-related potential assessment of sensory and cognitive deficits in the mentally retarded.
In D. Lehmann \& E. Callaway (Eds.), Human evoked potentials: Applications and problems (pp. 397-413). New York: Plenum Press. StePHENSON, D., SIDDLE, D. (1983). Theories of habituation. In D. Siddle (Ed.), Orienting and habituation: Perspectives in human research (pp. 183-236). New York: Wiley.

TUETING, P., LEVIT, R. A. (1979). Long-term changes of event-related potentials in normals, depressives and schizophrenics. In J. E. Desmedt (Ed.), Cognitive components in cerebral event-related potentials and selective attention. Progress in clinical neurophysiology (Vol. 6, pp. 265-279). Basel: Karger.

VERBATEN, M. N. (1983). The influence of information on habituation of cortical, autonomic and behavioral components of the orienting response (OR). In A. W. K. Gaillard \& W. Ritter (Eds.), Tutorials in ERP research: Endogenous components (pp. 201-216). Amsterdam: North-Holland Publishing.

Verbaten, M. N., Roelofs, J. W., Sjouw, W., Slangen, J. L. (1986). Different effects of uncertainty and complexity on single trial visual ERPs and the SCR-OR in non-signal conditions. Psychophysiology, 23, 254-262.

WEBER, B. A. (1970). Habituation and dishabituation of the averaged auditory evoked response. Journal of Speech \& Hearing Research, 13, 387-394.

Westenberg, I. S., * Weinberger, N. M. (1976). Evoked potential decrements in auditory cortex: II. Critical test for habituation. Electroencephalography \& Clinical Neurophysiology, 40, 356-369.

Wickens, C., Kramer, A., Vanasse, L., Donchin, E. (1983). The performance of concurrent tasks: A psychophysiological analysis of the reciprocity of information processing resources. Science, 221 , 1080-1082.

Wilkinson, R. T., \& SEALES, D. M. (1978). EEG event-related potentials and signal detection. Biological Psychology, 7, 13-28.

Wood, C. C., \& MCCARThY, G. (1984). Principal component analysis of event-related potentials: Simulation studies demonstrate misallocation of variance across components. Electroencephalography \& Clinical Neurophysiology, 59, 249-260.

Woods, D. L., Courchesne, E., Hillyard, S. A., \&alambos, R. (1980). Recovery cycles of event-related potentials in multiple detection tasks. Electroencephalography \& Clinical Neurophysiology, 50, 335-347.

Woods, D. L, Elmasian, R. (1986). The habituation of event-related potentials to speech sounds and tones. Electroencephalography \& Clinical Neurophysiology, 65, 447-459.

(Manuscript received January 13, 1988; revision accepted for publication September 2,1988 .) 